\title{
Progress of novel compounds with anticancer activity
}

\section{Jianping Yong ${ }^{1 *}$, Mingxue Yang ${ }^{2}$, Canzhong $\mathrm{Lu}^{1,2 *}$ and Xiaoyuan $\mathrm{Wu}^{2}$}

${ }^{1}$ Xiamen Institute of Rare-earth Materials, Chinese Academy of Sciences, China

${ }^{2}$ Fujian Institute of Research on the Structure of Matter, Chinese Academy of Sciences, China

Cancer is one of the major causes of human death worldwide. The death caused by cancer mainly is lung cancer, breast cancer, liver cancer, carcinoma of colon and rectum. It is estimated that about $1,688,780$ new cancer cases will be diagnosed in the United States in 2017 and 600,920 cancer cases are expected to die, which is about 1,650 people per day. For all sites combined, the cancer incidence rate is $20 \%$ higher in men than in women, while the cancer death rate is $40 \%$ higher [1]. It has been reported that 4,292,000 new cancer cases and 2,814,000 cancer deaths occurred in 2015 in China, with lung cancer being the most common incident cancer and the leading cause of cancer death. Stomach, esophageal, and liver cancers were also commonly diagnosed and were identified as leading causes of cancer death [2].

Some drugs have been available in the market for treatment cancer and several compounds are in different phases of clinical trials [3]. However, cancer chemotherapy is still highly inadequate. Thus it is urgent to develop novel anticancer agents.

In recent years, our research group focus on the design and synthesis of novel structures of anticancer compounds based on the quinazoline, thieno[2,3-d]pyrimidine and ferrocene cores, and we have achieved wonderful results [4]. We synthesized over 200 new compounds (Figure 1) and evaluated their in vitro anticancer activity. The results showed that most compounds exhibited the higher anticancer activity than that of the reference drug gefitinib. The excellent results showed in table 1. Some compounds can be regarded as the lead compounds or drug candidates for development of anticancer agents.

\section{Acknowledgements}

All works were financially supported by the National Natural Science Foundation of China (51672271).
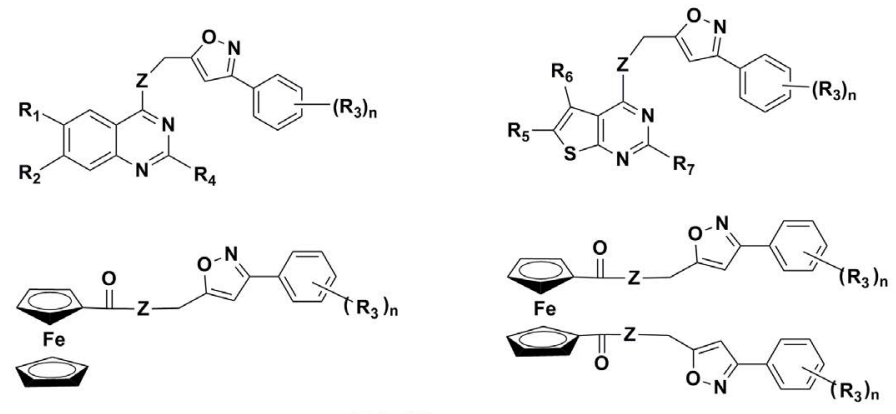

Z: O, NH

$\mathbf{R}_{1}, \mathbf{R}_{2}, \mathbf{R}_{4}, \mathbf{R}_{5}, \mathbf{R}_{6}, \mathbf{R}_{7}: \mathrm{H}, \mathrm{CH}_{3} \mathrm{O}, \mathrm{CH}_{3} \mathrm{OCH}_{2} \mathrm{CH}_{2} \mathrm{O}$,

$\mathrm{R}_{3}: \mathrm{H}, \mathrm{CH}_{3}, \mathrm{CH}_{3} \mathrm{CH}_{2}, \mathrm{Cl}, \mathrm{F}, \mathrm{CF}_{3}, \mathrm{NO}_{2}, \mathrm{Br}, \mathrm{OCH}_{3}, \mathrm{C}\left(\mathrm{CH}_{3}\right)_{3}$

Figure 1. Structures of newly synthesized compounds by us.
Table 1. Anticancer activity of the most potent compounds.

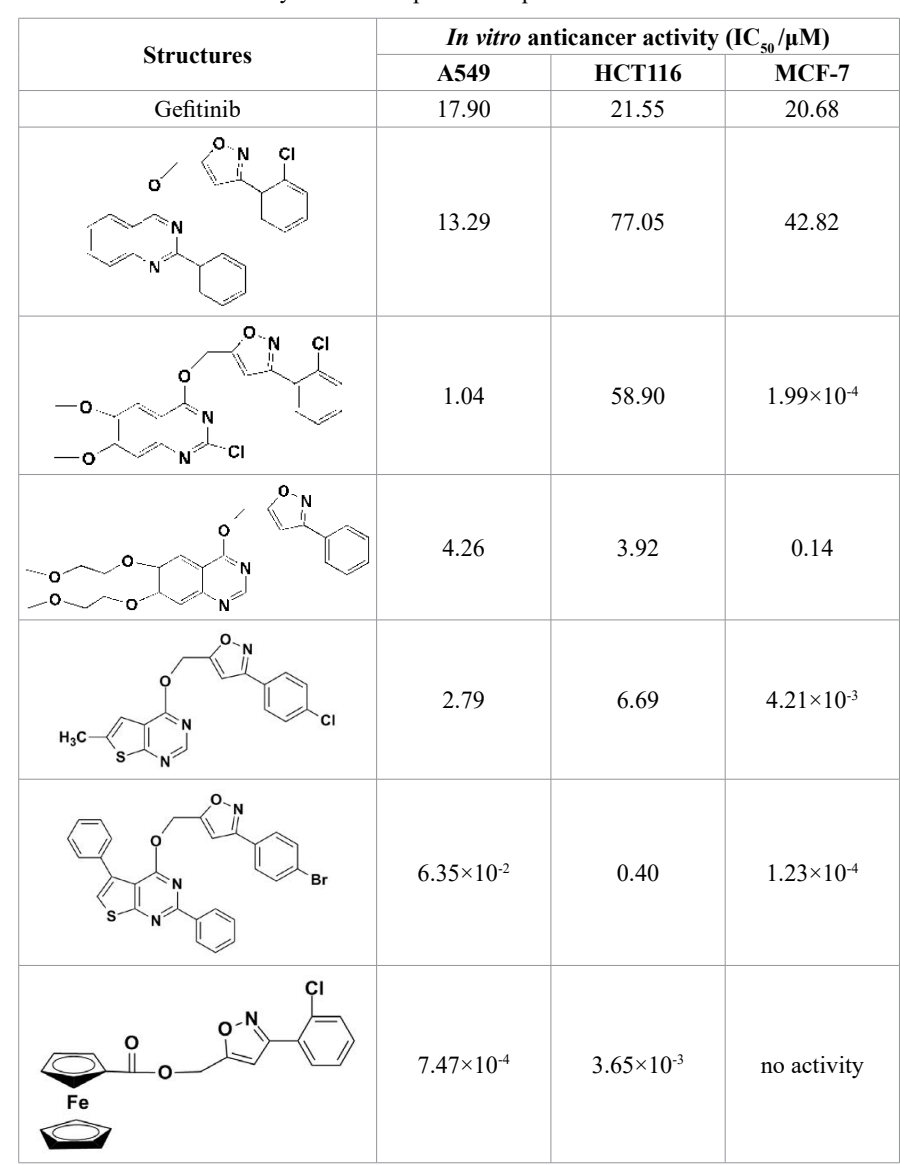

\section{References}

1. Siegel RL, Miller KD, Jemal A (2017) Cancer Statistics, 2017. CA Cancer J Clin 67: 7-30. [Crossref]

2. Chen W, Zheng R, Baade PD, Zhang S, Zeng H, et al. (2016) Cancer statistics in China, 2015. CA Cancer J Clin 66: 115-132. [Crossref]

*Correspondence to: Jianping Yong, Xiamen Institute of Rare-earth Materials, Chinese Academy of Sciences, Xiamen, 361021, China, Tel: +86-591-63173162, E-mail: jpyong@fjirsm.ac.cn

Canzhong Lu, Xiamen Institute of Rare-earth Materials, Chinese Academy of Sciences, Xiamen, 361021, China, Tel: +86-591-83705794, E-mail: czlu@firirsm. ac.cn

Received: March 05, 2018; Accepted: March 30, 2018; Published: April 03, 2018 
3. (a) Grosios K, Traxier P (2003) Tryosine kinase targets in drug discovery. Drugs future 28: 679-697;

(b) Qu SH (2012) Second-generation irreversible epidermal growth factor receptor (EGFR) tyrosine kinase inhibitors (TKIs): A better mousetrap? A review of the clinical evidence. Crit Rev Oncol Hemat 83: 407-421. [Crossref]

4. (a) Yong JP, Lu CZ, Wu X (2015) Potential anticancer agents I. synthesis of isoxazole moiety containing quinazoline derivatives and preliminarily in vitro anticancer activity. Anticancer agents Med Chem 15: 131-136. [Crossref]

(b) Yong J, Lu C, Wu X (2015) Synthesis and biological evaluation of quinazoline derivatives as potential anticancer agents (II). Anticancer agents Med Chem 15: 13261332. [Crossref]

(c) Yong J, Lu C, Wu X (2018) Synthesis and preliminarily cytotoxicity to A549, HCT116 and MCF-7 cell lines of thieno[2,3-d]pyrimidine derivatives containing Isoxazole moiety. Lett Drug Des Discov 15: 463-474. (d) Yong J, Lu C, Wu X (2015) Synthesis of isoxazole moiety containing thieno[2,3d]-pyrimidine derivatives and preliminarily in vitro anticancer activity (Part II). Anticancer agents Med Chem 15: 1148-1155; [Crossref]

(e) Yong J, Lu C, Wu X (2014) Synthesis of Isoxazole Moiety Containing Ferrocene Derivatives and Preliminarily in vitro Anticancer Activity. Med Chem Comm 5: 968-972.

(f) Yong J, Yang M, Lu C, Wu X (2018) Synthesis of 1,1'-ferrocene diformates bearing isoxazole moiety and preliminarily cytotoxicity to A549, HCT116 and MCF-7 cell lines. Lett Drug Des Discov 15.

(g) Lu C, Yong J. Quinazoline derivatives and application thereof. PCT/ WO2013143319A1;U. S. patent: 9193718B2; EP 2752413B1; ZL201210526123.X.

(h) Lu C, Yong J. Thieno[2,3-d]Pyrimidine derivatives, preparation method and use Thereo. PCT/WO2014043866A1;U. S patent: 9434741B2; EP 2835372B1; ZL201210349508.3.

(i) Yong J, Lu C. Ferrocene drivatives, preparation method and use thereof. U. S. patent: 9738673B1.

Copyright: (C2018 Yong J. This is an open-access article distributed under the terms of the Creative Commons Attribution License, which permits unrestricted use, distribution, and reproduction in any medium, provided the original author and source are credited. 